\title{
The effect of the formyl group position upon asymmetric isomeric diarylethenes bearing a naphthalene moiety
}

\author{
Renjie Wang, Shouzhi Pu ${ }^{*}$, Gang Liu and Shiqiang Cui
}

\author{
Full Research Paper \\ Address: \\ Jiangxi Key Laboratory of Organic Chemistry, Jiangxi Science \& \\ Technology Normal University, Nanchang 330013, PR China \\ Email: \\ Shouzhi Pu* - pushouzhi@tsinghua.org.cn \\ * Corresponding author \\ § Tel.: +86-791-83831996; Fax: +86-791-83831996 \\ Keywords: \\ chemical diversity; diarylethene; electrochemistry; formyl group; \\ photochromism; substituent position effect
}

Open Access

\author{
Beilstein J. Org. Chem. 2012, 8, 1018-1026. \\ doi:10.3762/bjoc. 8.114 \\ Received: 20 February 2012 \\ Accepted: 19 June 2012 \\ Published: 05 July 2012 \\ This article is part of the Thematic Series "Molecular switches and cages". \\ Guest Editor: D. Trauner \\ (C) 2012 Wang et al; licensee Beilstein-Institut. \\ License and terms: see end of document.
}

\begin{abstract}
Three new isomeric asymmetric diarylethenes with a naphthyl moiety and a formyl group at the para, meta or ortho position of the terminal benzene ring were synthesized. Their photochromism, fluorescent-switch, and electrochemical properties were investigated. Among these diarylethenes, the one with a formyl group at the ortho position of benzene displayed the largest molar absorption coefficients and fluorescence quantum yield. The cyclization quantum yields of these compounds increased in the order of para $<$ ortho $<$ meta, whereas their cycloreversion quantum yields decreased in the order of meta $>$ para $>$ ortho. Additionally, all of these diarylethenes functioned as effective fluorescent switches in both solution and PMMA films. Cyclic voltammograms proved that the formyl group and its position could effectively modulate the electrochemical behaviors of these diarylethene derivatives.
\end{abstract}

\section{Introduction}

In the past decade, photochromic materials have received much attention because of their applications in potential photoswitchable, molecular devices and optical memory storage systems [1]. Among these materials, the utilization of diarylethene derivatives in molecular electronics, optical memory, and variable-transmission filters has been well documented [1-3]. So far, a huge number of studies concerning the photochromic properties of dithienylethene derivatives have been reported [4-14].

Light is a convenient and powerful trigger to control the reactivity of biomolecules in organisms, exemplified by its use in fluorescent probes, fluorescence imaging, and molecular switches in logic circuits [15-22]. In general, in order to efficiently realize the artificial induction of photosensitivity in biomolecules, the photoactive molecules must possess the following properties: (1) low cytotoxicity, (2) high sensitivity, (3) easy chemical modification. In the past few decades, various types of photochromic molecules, such as fulgides, spiro- 
pyranes, azobenzenes, and diarylethenes, have been developed [2,23-31].

Among these compounds, diarylethene is one of the most promising photoswitchable units within the photochromic system, and the successful use of diarylethenes as a fluorescence modulation center to realize a photoswitchable probe for imaging living cells was reported. For example, Zou et al. reported an amphiphilic molecule with hydrophilic and hydrophobic chains on two ends of a rigid diarylethene core. This compound can form stable vesicle nanostructures in aqueous solution, and exhibits excellent switchable fluorescence between open and closed states in the living cells, with low cytotoxicity [32]. Piao et al. developed a multiresponsive fluorescent molecular switch containing terpyridine. This diarylethene can serve as a detector for metal-ion transmembrane transport [33]. Singer et al. explored a novel diarylethene with a 7-deazaadenosine, which led to new research in photochromic nucleosides and molecular recognition properties of nucleic acids with the light sensitivity of diarylethenes [34]. Recently, $\mathrm{Wu}$ et al. designed and synthesized a novel diarylethenecontaining dithiazolethene, which exhibited a gated photochromic reactivity controlled by complexation/dissociation with $\mathrm{BF}_{3}$ [35]. All of the above research revealed that the explored novel diarylethenes have versatile applications and are still important and attractive.

Diarylethene derivatives, especially those containing a perfluorocyclopentene bridge are one of the most promising photochromic compounds due to their high fatigue resistance and thermal stability $[2,36]$. In general, the photochromic reactivity of diarylethenes mainly depends on heteroaryl groups and different electron-donor/acceptor substituents. The formyl group can be modified to form various chemical groups and it can also be connected with different fluorophores via a Schiff base structure. In a previous work, we developed a new class of diarylethenes with a naphthalene group and a thiophene group.
The results revealed that these molecules have excellent photochromism with good fatigue resistance and thermal stability [37]. In this study, in order to further elucidate the substituent position effects on the photochromic features of naphthalene-containing diarylethenes, we synthesized three new isomeric diarylethenes with a formyl group at the para, meta, and ortho position on the terminal benzene ring (1-3). The photochromic scheme of $\mathbf{1 - 3}$ is shown in Scheme 1 .

\section{Results and Discussion}

The synthesis route for diarylethenes 10-3o is shown in Scheme 2. First, the benzaldehydethiophene derivatives 5a-c were prepared by Suzuki coupling of three bromobenzaldehyde derivatives with a thiopheneboronic acid 4 [38-42]. Second, 1,3-dioxolane-phenylthiophene derivatives $\mathbf{6 a - c}$ were prepared by the reported method [39-41,43]. Then, 1,3-dioxolanephenylthiophene derivatives $\mathbf{6 a - c}$ were separately lithiated and coupled with (2-methylnaphth-1-yl)perfluorocyclopentene [37] to give the asymmetric diarylethene derivatives $7 \mathbf{a}-\mathbf{c}$ [44]. Finally, compounds 10-3o were prepared by hydrolyzing compounds $7 \mathbf{a}-\mathbf{c}$ in the presence of pyridine and $p$-toluenesulfonic acid in acetone/water. The structures of 10-3o were confirmed by elemental analysis, NMR, and IR (Supporting Information File 1).

\section{Photoisomerization of diarylethenes 1-3}

Diarylethenes 1-3 showed good photochromic properties and could be toggled between their colorless open-ring isomers $(\mathbf{1 0}-\mathbf{3 o})$ and colored closed-ring isomers $(\mathbf{1 c}-\mathbf{3 c})$ by alternate irradiation with $U V$ and visible light $(\lambda>500 \mathrm{~nm})$. As shown in Figure 1A, diarylethene 10 exhibited a sharp absorption peak at $323 \mathrm{~nm}\left(\varepsilon, 2.82 \times 10^{4} \mathrm{~L} \mathrm{~mol}^{-1} \mathrm{~cm}^{-1}\right)$ in hexane, which arose from the $\pi \rightarrow \pi^{*}$ transition [45]. Upon irradiation with $297 \mathrm{~nm}$ light, the colorless solution of $\mathbf{1 0}$ gradually turned red, and a new absorption band was observed in the visible region centered at $524 \mathrm{~nm}\left(\varepsilon, 1.40 \times 10^{4} \mathrm{~L} \mathrm{~mol}^{-1} \mathrm{~cm}^{-1}\right)$ due to the formation of the closed-ring isomer 1c. Alternatively, the red-

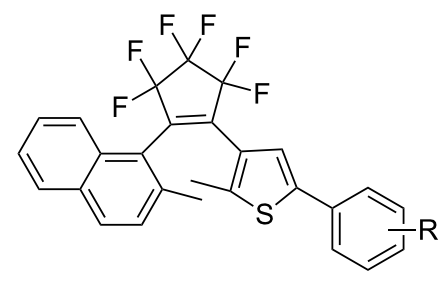

10: $\mathrm{R}=$ para $-\mathrm{CHO}$

2o: $\mathrm{R}=$ meta $-\mathrm{CHO}$

3o: $\mathrm{R}=$ ortho- $\mathrm{CHO}$

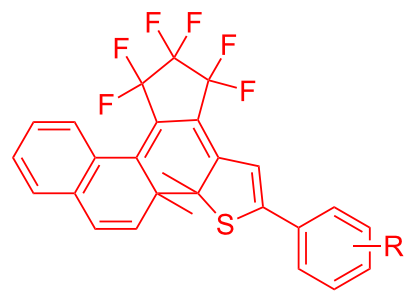

1c: $\mathrm{R}=$ para $-\mathrm{CHO}$

2c: $\mathrm{R}=$ meta $-\mathrm{CHO}$

3c: $\mathrm{R}=$ ortho- $\mathrm{CHO}$ 


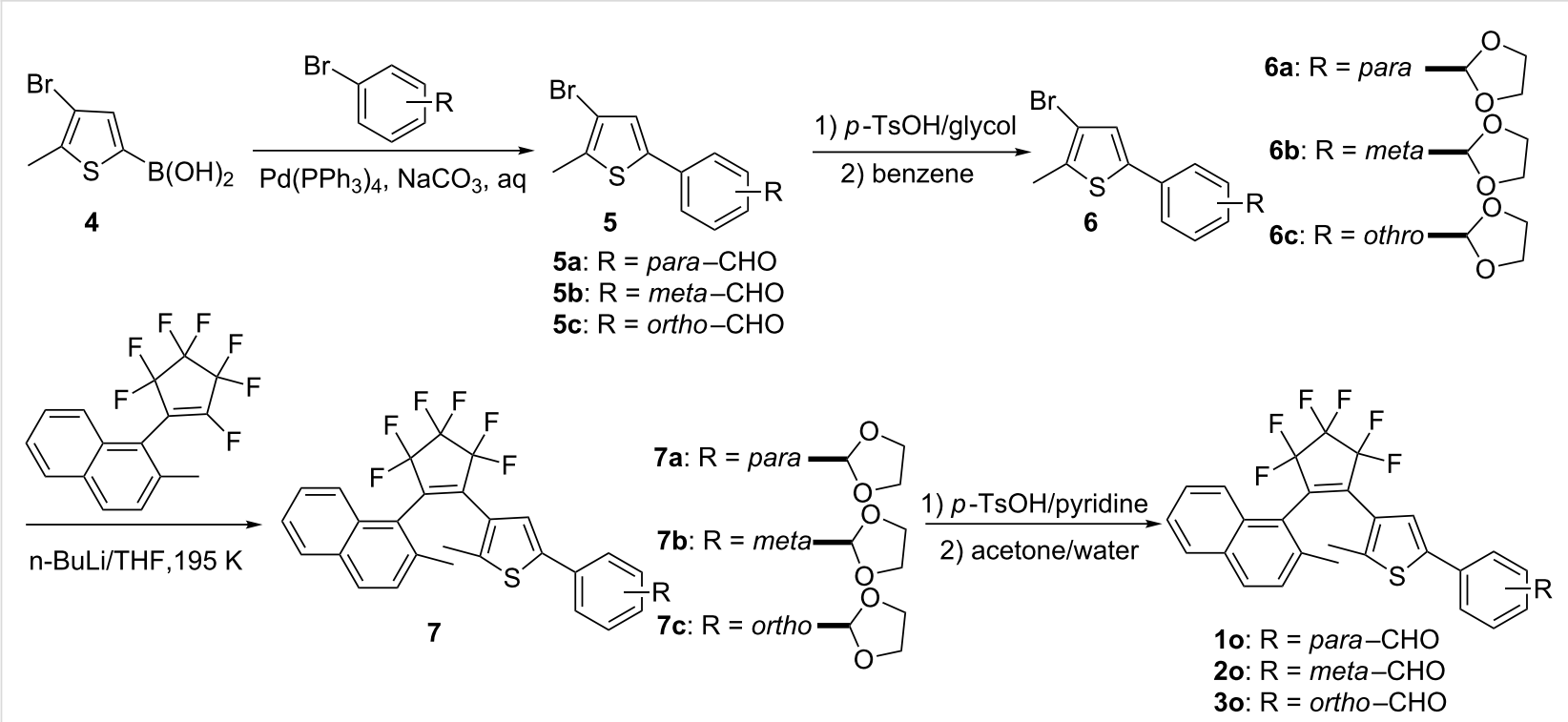

Scheme 2: Synthetic route for diarylethenes 1-3.

colored solution could be bleached to become colorless by re-production of the open-ring isomer 10 upon irradiation with visible light $(\lambda>500 \mathrm{~nm})$. In the photostationary state, a clear isosbestic point of diarylethene $\mathbf{1}$ was observed at $349 \mathrm{~nm}$, which supported the reversible two-component photochromic reaction scheme [46]. Similarly 1o, compounds 20 and $\mathbf{3 o}$ also showed good photochromism in hexane (Figure 1B). The colorless solutions of $\mathbf{2 o}$ and $\mathbf{3 o}$ turned pink and magenta due to the formation of the closed-ring isomers $\mathbf{2 c}$ and $\mathbf{3 c}$, when irradiated with $297 \mathrm{~nm}$ light. Their absorption maxima appeared at 512 and $496 \mathrm{~nm}$ respectively. The colored solutions of $\mathbf{2 c}$ and $\mathbf{3 c}$ can also be decolorized upon irradiation with visible light $(\lambda>500 \mathrm{~nm})$, and their isosbestic points were observed at 277 and $268 \mathrm{~nm}$, respectively. The color changes of diarylethenes 1-3 by alternating irradiation with $\mathrm{UV}$ and visible light $(\lambda>500 \mathrm{~nm})$ in hexane are shown in Figure 2A.

In PMMA amorphous films, diarylethenes 1-3 also showed similar photochromic activity to that in hexane. The absorption maxima of closed-ring isomers of diarylethenes $\mathbf{1 c}-\mathbf{3 c}$ in PMMA films were at longer wavelengths. The values of the absorption maxima of the ring-closed isomers are $14 \mathrm{~nm}$ for $\mathbf{1 c}$, $7 \mathrm{~nm}$ for $\mathbf{2 c}$, and $21 \mathrm{~nm}$ for $\mathbf{3 c}$. The redshift phenomena may be ascribed to a polar effect of the polymer matrix and the stabilization of the molecular arrangement in the solid medium $[47,48]$. The color changes of diarylethenes $\mathbf{1}-\mathbf{3}$ upon alter-
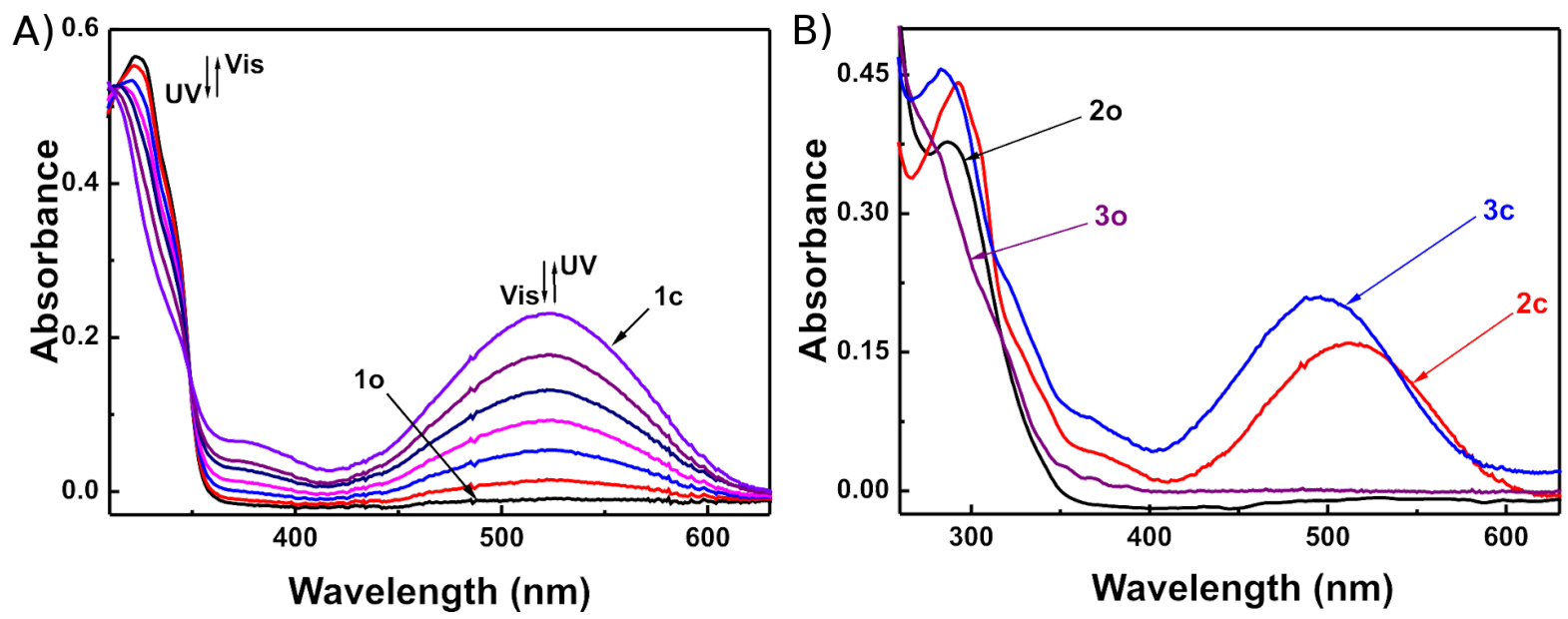

Figure 1: Absorption spectral changes of diarylethenes 1-3 by photoirradiation with UV-vis in hexane $\left(2.0 \times 10^{-5} \mathrm{~mol} / \mathrm{L}\right)$ at room temperature: (A) 1 ; (B) 2 and 3. 
A)

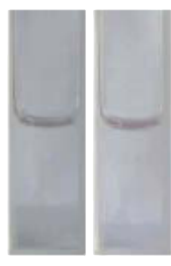

1020

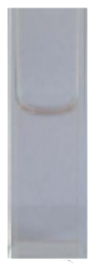

30

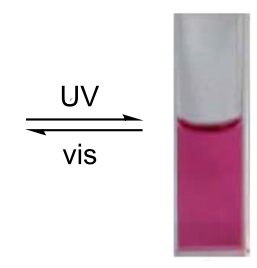

1c $2 c$

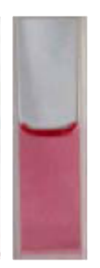

2c $3 c$
B)

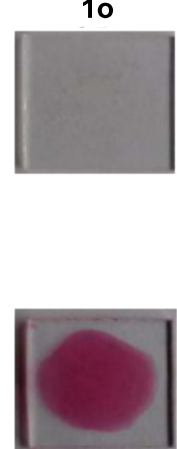

$1 c$
20

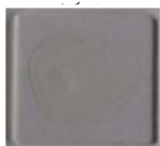

vis 1 UV

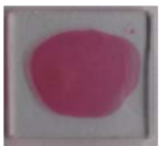

2c
30
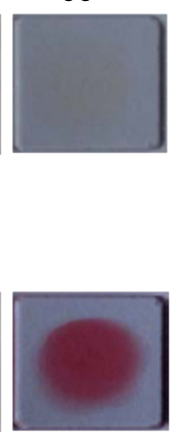

3c

Figure 2: The color changes of diarylethene 1-3 by photoirradiation at room temperature: $(A)$ in hexane; (B) in PMMA films.

nating irradiation with UV and visible light in PMMA films are shown in Figure 2B. The photoconversion ratios from open-ring to closed-ring isomers of $\mathbf{1}-\mathbf{3}$ were analyzed by HPLC in the photostationary state (Figure 3 ). It was calculated that their photoconversion ratios in the photostationary state were $82 \%$ for $\mathbf{1}, 79 \%$ for $\mathbf{2}$, and $81 \%$ for $\mathbf{3}$.

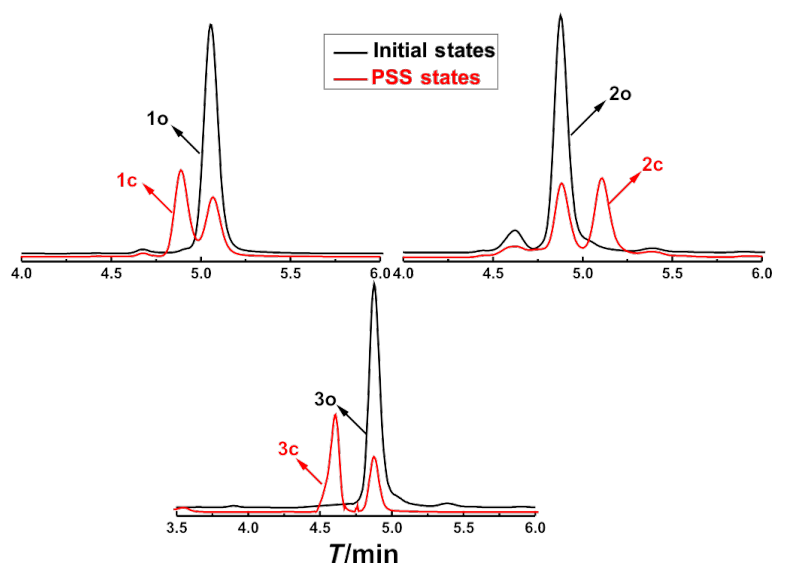

Figure 3: The photoconversion ratios of diarylethenes 1-3 in the photostationary state as analyzed by HPLC.
The photochromic features of compounds 1-3 are summarized in Table 1. The results indicate that the position of the formyl group at the terminal benzene significantly affects the photochromic properties of these diarylethenes, such as the absorption maxima, molar absorption coefficients, and quantum yields of cyclization and cycloreversion. For the isomeric diarylethenes 1-3, the absorption maxima of both the open-ring and closed-ring isomers exhibited a remarkable hypochromatic shift when the formyl group was moved from the para to the meta, then to the ortho position in both hexane and PMMA films, whereas the molar absorption coefficients of diarylethenes 1-3 increased in order of meta $<$ para $<$ ortho substitution by the formyl group in hexane. The results were in agreement with those of the reported diarylethenes containing an electron-withdrawing cyano group [49], but were different from those with an electron-donating methoxy group $[14,50,51]$. The cycloreversion quantum yields of diarylethenes 1-3 increased in the order of ortho $\left(\Phi_{\mathrm{c}-\mathrm{o}}=0.11\right)<$ para $\left(\Phi_{\mathrm{c}-\mathrm{o}}=\right.$ $0.12)<$ meta substitution $\left(\Phi_{\mathrm{c}-\mathrm{o}}=0.15\right)$ by the formyl group. However, the cyclization quantum yield of the para-substituted derivative 1 was the largest $\left(\Phi_{\mathrm{c}-\mathrm{o}}=0.35\right)$, while that of the meta-substituted derivative 2 was the lowest $\left(\Phi_{\mathrm{c}-\mathrm{o}}=0.21\right)$. Compared to the electron-donating methoxy group or electronwithdrawing cyano group $[49,50]$, the position of the electron-

Table 1: Absorption spectral properties of diarylethenes 1-3 in hexane $\left(2.0 \times 10^{-5} \mathrm{~mol} \mathrm{~L}^{-1}\right)$ and in PMMA films (10\%, w/w) at room temperature.

\begin{tabular}{|c|c|c|c|c|c|c|c|}
\hline \multirow{2}{*}{ compound } & \multicolumn{2}{|c|}{$\lambda_{o, \max } / \mathrm{nm}^{\mathrm{a}}\left(\varepsilon / \mathrm{L} \mathrm{mol}^{-1} \mathrm{~cm}^{-1}\right)$} & \multicolumn{2}{|c|}{$\lambda_{\mathrm{c}, \max } / \mathrm{nm}^{\mathrm{b}}\left(\varepsilon / \mathrm{L} \mathrm{mol}^{-1} \mathrm{~cm}^{-1}\right)$} & \multicolumn{2}{|c|}{$\Phi^{c}$} & \multirow{2}{*}{$\begin{array}{c}\text { conversion at PSS in } \\
\text { hexane }\end{array}$} \\
\hline & hexane & PMMA film & hexane & PMMA film & $\Phi_{\mathrm{O}-\mathrm{C}}$ & $\Phi_{\mathrm{C}-\mathrm{O}}$ & \\
\hline 1 & $323\left(2.82 \times 10^{4}\right)$ & 326 & $524\left(1.40 \times 10^{4}\right)$ & 538 & 0.35 & 0.12 & 82 \\
\hline 2 & $256\left(2.75 \times 10^{4}\right)$ & 288 & $512\left(1.01 \times 10^{4}\right)$ & 519 & 0.21 & 0.15 & 79 \\
\hline 3 & $245\left(3.48 \times 10^{4}\right)$ & 248 & $496\left(1.57 \times 10^{4}\right)$ & 517 & 0.25 & 0.11 & 81 \\
\hline
\end{tabular}

aAbsorption maxima of ring-open isomers. ${ }^{b}$ Absorption maxima of ring-closed isomers. ${ }^{c}$ Quantum yields of ring-open ( $\left.\Phi_{\mathrm{O}-\mathrm{c}}\right)$ and ring-closed isomers $\left(\Phi_{\mathrm{C}-\mathrm{o}}\right)$, respectively. 
withdrawing formyl group can effectively modulate the absorption maxima of diarylethenes, which may be a novel strategy for exploring photochromic diarylethenes at shorter wavelengths.

The thermal stabilities of the open-ring and closed-ring isomers of 1-3 were tested by storing the compounds at both room temperature in hexane and at $351 \mathrm{~K}$ in ethanol. The hexane solutions were kept at room temperature in the dark, and exposed to air for more than two months. No changes in the UV-vis spectra were observed for $\mathbf{1}-\mathbf{3}$. At $351 \mathrm{~K}$, diarylethenes 1-3 also showed excellent thermal stability for more than $12 \mathrm{~h}$ in ethanol. Fatigue resistance is a critical factor for practical applications in optical devices, and the fatigue resistances of diarylethenes 1-3 were examined in both hexane and PMMA films by alternate irradiation with UV and visible light at room temperature [2,52]. As shown in Figure 4, the coloration and decoloration cycle of 1-3 can be repeated more than 100 times in hexane with less than $5 \%$ degradation of $\mathbf{1 c - 3 c}$. In PMMA films, 1-3 also exhibited excellent photochromic properties after 200 cycles with only ca. $6-10 \%$ degradation of $1 \mathbf{c}-\mathbf{3 c}$. The results showed that all three isomeric diarylethenes 1-3 had good fatigue resistance in both hexane and PMMA films.

\section{Fluorescence of diarylethenes 1-3}

Fluorescence can be used not only in molecular-scale optoelectronics but also in digital photoswitching [22,53,54]. Like most of reported diarylethenes, diarylethenes 1-3 exhibited notable fluorescence in both hexane and PMMA films. Their fluorescence spectra were measured at room temperature with a Hitachi F-4500 spectrophotometer (Figure 5). In hexane, the emission peaks of 10-3o were observed at 384, 387, and
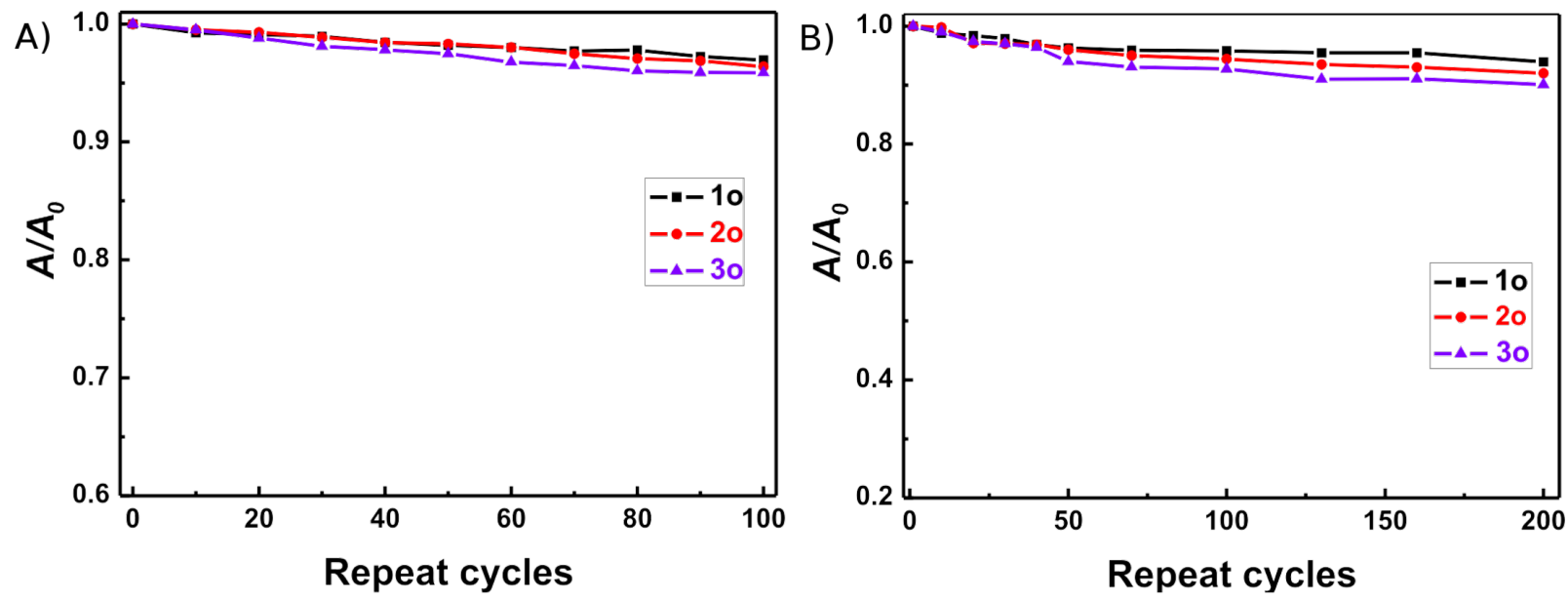

Figure 4: Fatigue resistance of diarylethenes 1-3 in hexane in air atmosphere at room temperature: (A) in hexane; (B) in PMMA films. Initial absorbance of the sample was fixed to 1.0 .
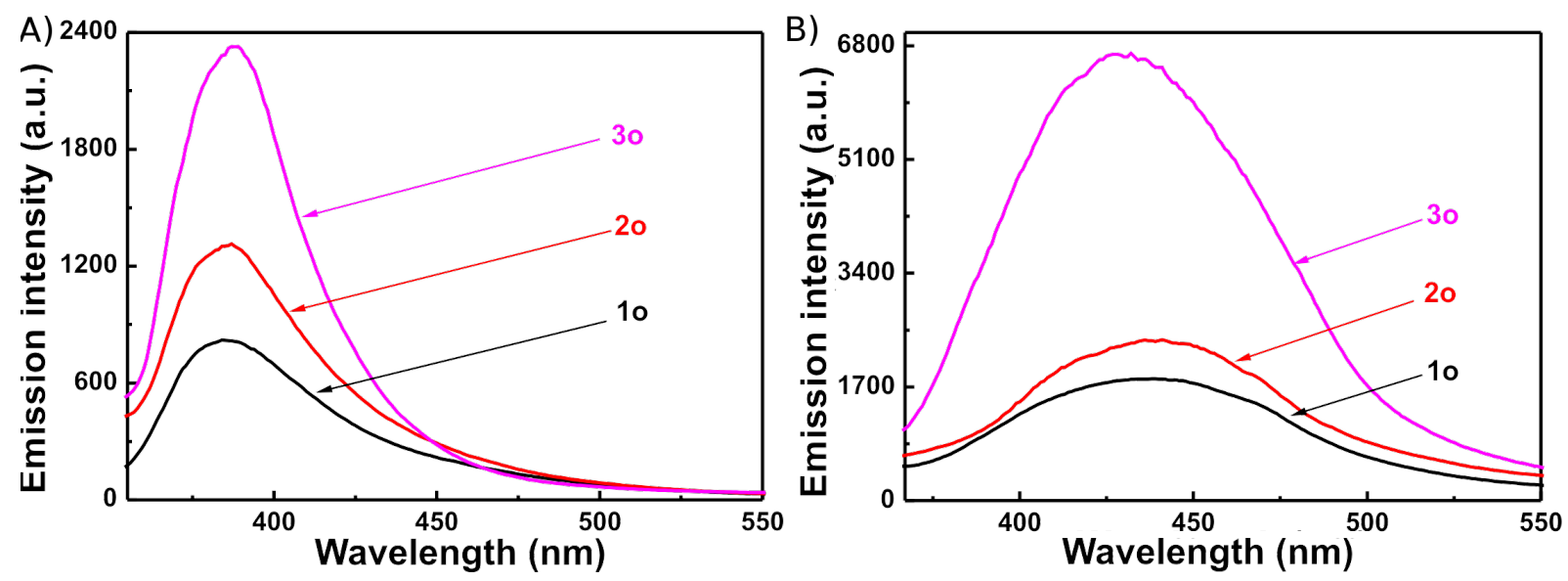

Figure 5: Fluorescence emission spectra of diarylethenes 1-3 at room temperature: $(A)$ in hexane solution $\left(2.0 \times 10^{-5} \mathrm{~mol} \mathrm{~L}^{-1}\right)$; $(\mathrm{B})$ in $\mathrm{PMMA}$ films $(10 \%, w / w)$. 
$389 \mathrm{~nm}$, when excited at 307,315 , and $300 \mathrm{~nm}$, whereas those in PMMA films were observed at 438, 441, and $427 \mathrm{~nm}$, when excited at 334,300 , and $300 \mathrm{~nm}$ respectively. In comparison with those of 1o-3o in hexane, the fluorescence emission peaks of 10-3o in PMMA films consistently exhibited a remarkable bathochromic shift. The emission intensity of the ortho-substituted derivative 30 was the strongest, while that of the parasubstituted derivative 10 was the weakest in both hexane and PMMA films. Compared to the unsubstituted parent diarylethene, 1-(2-methylnaphth-1-yl)-2-[2-methyl-5-phenylthien-3yl]perfluorocyclopentene $\left(\Phi_{\mathrm{f}}=0.011\right)$ [37], the fluorescence emission intensities of diarylethenes 10 and $\mathbf{2 0}$ were decreased, but that of 30 was evidently increased. When anthracene was used as the reference, the fluorescence quantum yields of 1o-3o were determined to be $0.012,0.018$, and 0.059 , respectively, indicating that the formyl group on the terminal benzene ring could notably enhance the fluorescence quantum yield and remarkably influence the fluorescence emission intensity of diarylethenes with a naphthalene moiety.

Diarylethenes 1-3 exhibited an evident fluorescence switching capability upon changing from the open-ring to the closed-ring isomers by photoirradiation in both hexane and PMMA films. When irradiated by UV light, the photocyclization reaction yielded the nonfluorescent closed-ring isomers $\mathbf{1 c}-\mathbf{3 c}$, resulting in a decrease in emission intensity as compared to the open-ring isomers 1o-3o. The back irradiation by visible light of appropriate wavelength $(\lambda>500 \mathrm{~nm})$ regenerated the open-ring isomers 10-3o, and recovered their original emission intensity. As shown in Figure 6, upon irradiation with UV light, the emission intensity of 1 decreased, and was quenched to ca. $59 \%$ in hexane and $35 \%$ in a PMMA film, when it arrived at the photostationary state. The fluorescent modulation efficiency in the photostationary state was $41 \%$ in hexane and $65 \%$ in a PMMA film. Similarly, in the photostationary state, the fluorescence modulation efficiencies of diarylethenes $\mathbf{2}$ and $\mathbf{3}$ in hexane were 73 and $78 \%$, and those in PMMA films were 38 and $42 \%$, respectively. The residual fluorescence for $\mathbf{1}-\mathbf{3}$ in the photostationary state may be attributed to an incomplete cyclization reaction and the existence of parallel conformations $[55,56]$. Among the three isomeric derivatives, the fluorescent modulation efficiency of diarylethene $\mathbf{2}$ was the largest and that of $\mathbf{1}$ was the smallest in PMMA films, suggesting that the diarylethene $\mathbf{2}$ is the best candidate for the fluorescence photoswitching material.

\section{Electrochemical properties of diarylethenes 1-3}

The electrochemical behaviors of diarylethene derivatives have attracted much attention because of their potential applications in molecular-scale electronic switches [57-62]. The electrochemical properties of 1-3 were evaluated by cyclic voltammetry $(\mathrm{CV})$ under the same experimental conditions reported previously [13]. The CV curves of diarylethenes $\mathbf{1}-\mathbf{3}$ are shown in Figure 7. The onset potentials ( $\left.E_{\text {onset }}\right)$ of oxidation and reduction for $\mathbf{1 0}$ were initiated at +1.79 and $-0.89 \mathrm{~V}$, and those of $\mathbf{1 c}$ at +1.76 and $-0.91 \mathrm{~V}$, respectively. According to the reported method $[63,64]$, the ionization potential and electron affinities of 10 were calculated to be -6.59 and $-4.09 \mathrm{eV}$, and those of $\mathbf{1 c}$ were -6.56 and $-3.89 \mathrm{eV}$. Based on the highest occupied molecular orbital (HOMO) and lowest unoccupied molecular orbital (LUMO) energy level, the band gap $E_{\mathrm{g}}\left(E_{\mathrm{g}}=\right.$ LUMO-HOMO) of 10 and $1 \mathrm{c}$ can be determined to be +2.50 and $+2.67 \mathrm{eV}$. Similarly, the oxidation potential of $\mathbf{2 0}$ and $\mathbf{3 0}$ is initiated at +1.76 and $+1.83 \mathrm{~V}$, and that of $\mathbf{2 c}$ and $3 \mathbf{c}$ is initiated at +1.74 and $+1.79 \mathrm{~V}$. The results indicate that the oxidation process for the
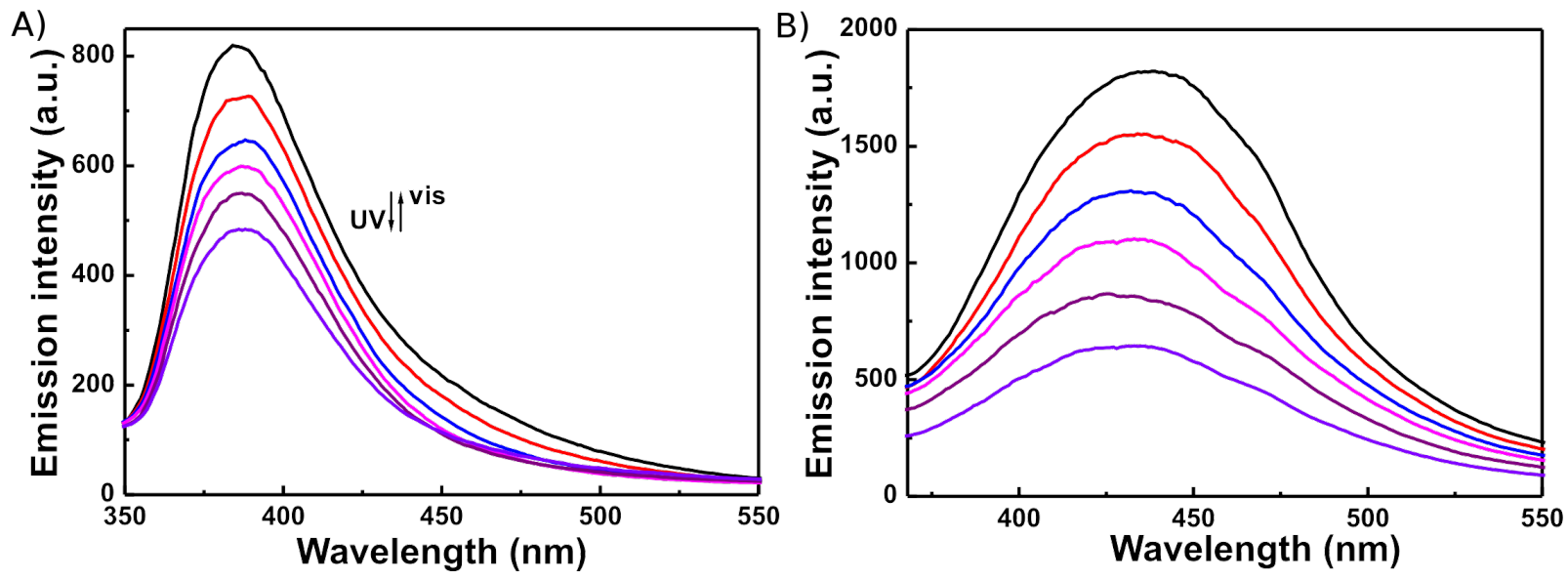

Figure 6: Emission intensity changes of diarylethene 1 upon irradiation with UV light at room temperature: (A) in hexane (excited at $307 \mathrm{~nm})$, (B) in a PMMA film (excited at $324 \mathrm{~nm}$ ). 


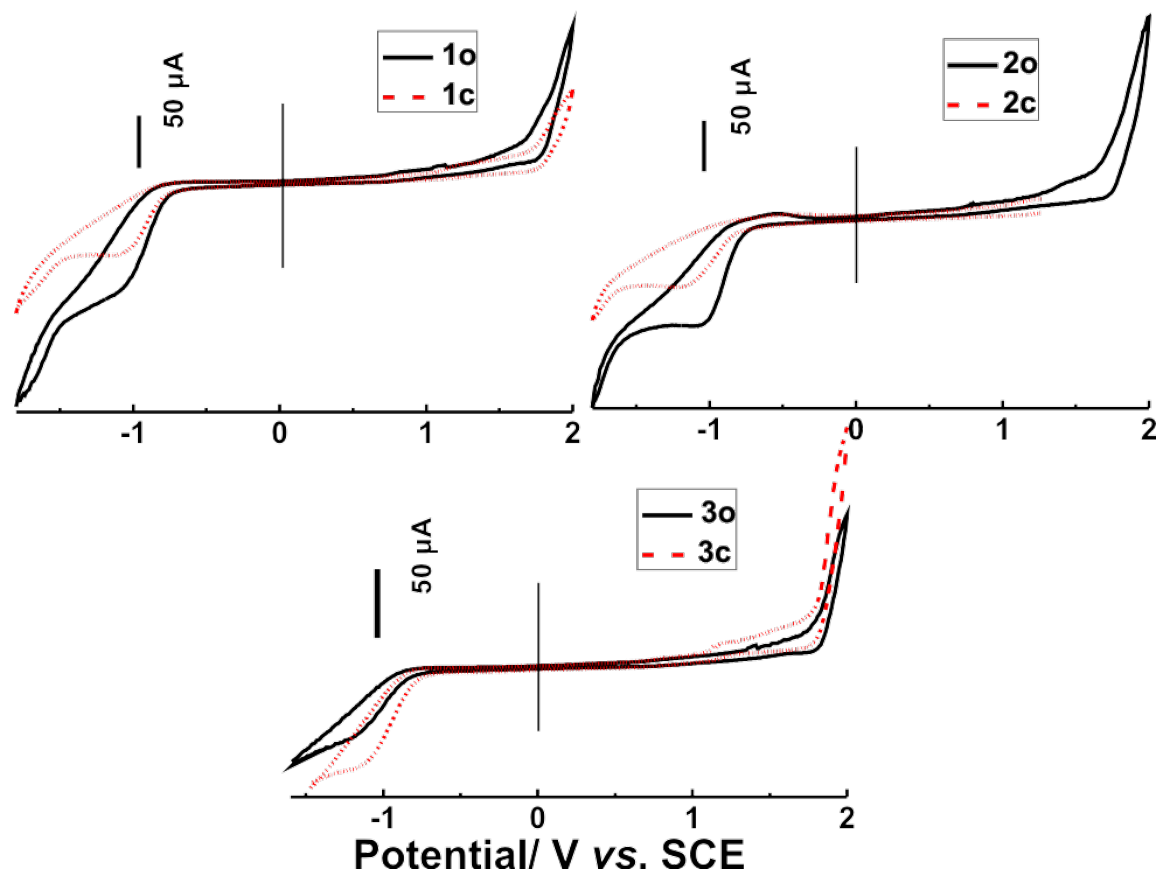

Figure 7: Cyclic voltammetry of diarylethenes 1-3 in acetonitrile with a scanning rate of $50 \mathrm{mV} / \mathrm{s}$.

open-ring isomers 10-3o occurs at higher potentials than in the corresponding closed-ring isomers $\mathbf{1 c - 3 c}$. This was because the longer conjugation length of the closed-ring isomers generally leads to a less positive potential $[62,65]$. The cyclization reaction allows the $\pi$-conjugation to extend across the perfluorocyclopentene ring causing a lower oxidation onset. As shown in Table 2, for the band gap of diarylethenes $\mathbf{1}$ and $\mathbf{2}$, the values of $E_{\mathrm{g}}$ of the open-ring isomers were lower than those of the closed-ring isomers, with the exception of $\mathbf{3}$. Among these compounds, the $E_{\mathrm{g}}$ of $\mathbf{1 0}$ was the smallest, which implies that the charge transfer of 10 was faster compared to that in others [66]. All these data suggest that the position of the formyl group at the terminal benzene ring has a remarkable effect on the electrochemical behaviors of these diarylethenes, but further work is required to quantify these effects.

\section{Conclusion}

Three new asymmetric isomeric diarylethenes containing a formyl group at either the para, meta, or ortho position of the terminal benzene ring were synthesized for the investigation of the effect of substituent position on their optical and electrochemical properties. The results revealed that the formyl group and its position had significant effects on the properties of these isomeric diarylethenes. The electron-withdrawing formyl group endowed these diarylethenes with some new properties, which were different from those of diarylethenes with a methoxy group or halide at the terminal benzene.

\begin{tabular}{|c|c|c|c|c|c|}
\hline \multirow[t]{2}{*}{ compound } & \multicolumn{2}{|c|}{ oxidation } & \multicolumn{2}{|c|}{ reduction } & \multirow{2}{*}{$\begin{array}{c}\text { band gap } \\
E_{\mathrm{g}}\end{array}$} \\
\hline & $\begin{array}{c}E_{\text {onset }} \\
(\mathrm{V})\end{array}$ & $\begin{array}{l}\text { IP } \\
(\mathrm{eV})\end{array}$ & $\begin{array}{c}E_{\text {onset }} \\
(\mathrm{V})\end{array}$ & $\begin{array}{l}\text { EA } \\
(\mathrm{eV})\end{array}$ & \\
\hline 10 & +1.79 & -6.59 & -0.89 & -4.09 & 2.50 \\
\hline $1 c$ & +1.76 & -6.56 & -0.91 & -3.89 & 2.67 \\
\hline 20 & +1.76 & -6.56 & -0.83 & -3.97 & 2.59 \\
\hline $2 c$ & +1.74 & -6.54 & -1.01 & -3.79 & 2.75 \\
\hline 30 & +1.83 & -6.63 & -0.87 & -3.93 & 2.70 \\
\hline $3 c$ & +1.79 & -6.59 & -0.80 & -4.00 & 2.59 \\
\hline
\end{tabular}

\section{Supporting Information}

\section{Supporting Information File 1}

Experimental procedures and spectral data.

[http://www.beilstein-journals.org/bjoc/content/

supplementary/1860-5397-8-114-S1.pdf]

\section{Acknowledgements}

This work was supported by the National Natural Science Foundation of China (20962008, 21162011), the Project of Jiangxi Academic and Technological Leader (2009DD00100), the Project of Jiangxi Youth Scientist, and the Project of the Science Funds of Jiangxi Education Office (GJJ10241, GJJ09646). 


\section{References}

1. Feringa, B. L., Ed. Molecular Switches; Wiley-VCH: Weinheim, Germany, 2001. doi:10.1002/3527600329.fmatter_indsub

2. Irie, M. Chem. Rev. 2000, 100, 1685-1716. doi:10.1021/cr980069d

3. Irie, M. Diarylethenes with Heterocyclic Aryl Groups. In Organic Photochromic and Thermochromic Compounds: Physicochemical Studies, Biological Applications, and Thermochromism; Crano, J. C.; Guglielmetti, R. J., Eds.; Plenum Press: New York, 1999; Vol. 1, pp 207-222.

4. Luo, Q.; Cheng, H.; Tian, H. Polym. Chem. 2011, 2, 2435-2443. doi:10.1039/c1py00167a

5. Norsten, T. B.; Branda, N. R. J. Am. Chem. Soc. 2001, 123, 1784-1785. doi:10.1021/ja005639h

6. Giordano, L.; Jovin, T. M.; Irie, M.; Jares-Erijman, E. A. J. Am. Chem. Soc. 2002, 124, 7481-7489. doi:10.1021/ja016969k

7. Liddell, P. A.; Kodis, G.; Moore, A. L.; Moore, T. A.; Gust, D. J. Am. Chem. Soc. 2002, 124, 7668-7669. doi:10.1021/ja026327c

8. Yamaguchi, T.; Irie, M. J. Org. Chem. 2005, 70, 10323-10328. doi:10.1021/jo051372z

9. Tsivgoulis, G. M.; Lehn, J.-M. Chem.-Eur. J. 1996, 2, 1399-1406. doi:10.1002/chem.19960021112

10. Pu, S.; Yang, T.; Xu, J.; Chen, B. Tetrahedron Lett. 2006, 47, 6473-6477. doi:10.1016/j.tetlet.2006.06.073

11. Fan, C.; Pu, S.; Liu, G.; Yang, T. J. Photochem. Photobiol., A: Chem. 2008, 194, 333-343. doi:10.1016/j.jphotochem.2007.08.032

12. Pu, S.; Yan, L.; Wen, Z.; Liu, G.; Shen, L. J. Photochem. Photobiol., A: Chem. 2008, 196, 84-93. doi:10.1016/j.jphotochem.2007.11.016

13. Pu, S.; Zheng, C.; Le, Z.; Liu, G.; Fan, C. Tetrahedron 2008, 64, 2576-2585. doi:10.1016/j.tet.2008.01.025

14. Pu, S.; Fan, C.; Miao, W.; Liu, G. Dyes Pigm. 2010, 84, 25-35. doi:10.1016/j.dyepig.2009.06.018

15. Goeldner, M.; Givens, R., Eds. Dynamic Studies in Biology: Phototriggers, Photoswitches and Caged Biomolecules; Wiley- $\mathrm{VCH}$ : Weinheim, Germany, 2005.

16. Gorostiza, P.; Isacoff, E. Y. Science 2008, 322, 395-399. doi:10.1126/science.1166022

17. Zou, Q.; Li, X.; Zhang, J.; Zhou, J.; Sun, B.; Tian, H. Chem. Commun. 2012, 48, 2095-2097. doi:10.1039/c2cc16942h

18. Finley, K. R.; Davidson, A. E.; Ekker, S. C. BioTechniques 2001, 31, 66-72.

http://www.biotechniques.com/multimedia/archive/00011/01311st02_11 391a.pdf

19. Zheng, Q.; Xu, G.; Prasad, P. N. Chem.-Eur. J. 2008, 14, 5812-5819. doi:10.1002/chem.200800309

20. Mottram, L. F.; Maddox, E.; Schwab, M.; Beaufils, F.; Peterson, B. R. Org. Lett. 2007, 9, 3741-3744. doi:10.1021/ol7015093

21. Miller, E. W.; Bian, S. X.; Chang, C. J. J. Am. Chem. Soc. 2007, 129, 3458-3459. doi:10.1021/ja0668973

22. Tian, H.; Feng, Y. J. Mater. Chem. 2008, 18, 1617-1622. doi:10.1039/B713216F

23. Willner, I.; Rubin, S.; Wonner, J.; Effenberger, F.; Baeuerle, P. J. Am. Chem. Soc. 1992, 114, 3150-3151. doi:10.1021/ja00034a078

24. Lion-Dagan, M.; Willner, I. J. Photochem. Photobiol., A: Chem. 1997, 108, 247-252. doi:10.1016/S1010-6030(97)00083-X

25. Sakata, T.; Yan, Y.; Marriott, G. Proc. Natl. Acad. Sci. U. S. A. 2005, 102, 4759-4764. doi:10.1073/pnas.0405265102

26. Weston, D. G.; Kirkham, J.; Cullen, D. C. Biochim. Biophys. Acta 1999, 1428, 463-467. doi:10.1016/S0304-4165(99)00099-9
27. Renner, C.; Moroder, L. ChemBioChem 2006, 7, 868-878. doi:10.1002/cbic.200500531

28. Volgraf, M.; Gorostiza, P.; Numano, R.; Kramer, R. H.; Isacoff, E. Y.; Trauner, D. Nat. Chem. Biol. 2005, 2, 47-52. doi:10.1038/nchembio756

29. Willner, I.; Rubin, S.; Riklin, A. J. Am. Chem. Soc. 1991, 113, 3321-3325. doi:10.1021/ja00009a016

30. Woolley, G. A. Chem. Res. 2005, 38, 486-493. doi:10.1021/ar040091v

31. Zhang, F.; Zarrine-Afsar, A.; Al-Abdul-Wahid, M. S.; Prosser, R. S.; Davidson, A. R.; Woolley, G. A. J. Am. Chem. Soc. 2009, 131, 2283-2289. doi:10.1021/ja807938v

32. Zou, Y.; Yi, T.; Xiao, S.; Li, F.; Li, C.; Gao, X.; Wu, J.; Yu, M.; Huang, C. J. Am. Chem. Soc. 2008, 130, 15750-15751. doi:10.1021/ja8043163

33. Piao, X.; Zou, Y.; Wu, J.; Li, C.; Yi, T. Org. Lett. 2009, 11, 3818-3821. doi:10.1021/ol9014267

34. Singer, M.; Jäschke, A. J. Am. Chem. Soc. 2010, 132, 8372-8377 doi:10.1021/ja1024782

35. Wu, Y.; Chen, S.; Yang, Y.; Zhang, Q.; Xie, Y.; Tian, H.; Zhu, W. Chem. Commun. 2012, 48, 528-530. doi:10.1039/c1cc15824d

36. Tian, H.; Yang, S. Chem. Soc. Rev. 2004, 33, 85-97. doi:10.1039/B302356G

37. Wang, R.; Pu, S.; Liu, G.; Liu, W.; Xia, H. Tetrahedron Lett. 2011, 52, 3306-3310. doi:10.1016/j.tetlet.2011.04.063

38. Li, Z.-X.; Liao, L.-Y.; Sun, W.; Xu, C.-H.; Zhang, C.; Fang, C.-J.; Yan, C.-H. J. Phys. Chem. C 2008, 112, 5190-5196. doi:10.1021/jp711613y

39. Yamamoto, S.; Matsuda, K.; Irie, M. Org. Lett. 2003, 5, 1769-1772. doi:10.1021/ol034440h

40. Yamamoto, S.; Matsuda, K.; Irie, M. Angew. Chem., Int. Ed. 2003, 42, 1636-1639. doi:10.1002/anie.200250417

41. Yamamoto, S.; Matsuda, K.; Irie, M. Chem.-Eur. J. 2003, 9 , 4878-4886. doi:10.1002/chem.200304947

42. Kuroki, L.; Takami, S.; Shibata, K.; Irie, M. Chem. Commun. 2005, 6005-6007. doi:10.1039/B512873K

43. Pu, S.; Li, M.; Liu, G.; Le, Z. Aust. J. Chem. 2009, 62, 464-474. http://www.publish.csiro.au/paper/CH08289

44. Wang, R. J.; Li, W. B.; Liu, W. J.; Liu, G. Adv. Mater. Res. 2012, 393-395, 381-384. doi:10.4028/www.scientific.net/AMR.393-395.381

45. Liu, G.; Pu, S.; Wang, X. J. Photochem. Photobiol., A: Chem. 2010, 214, 230-240. doi:10.1016/j.jphotochem.2010.07.001

46. Kawai, S.; Nakashima, T.; Atsumi, K.; Sakai, T.; Harigai, M.; Imamoto, Y.; Kamikubo, H.; Kataoka, M.; Kawai, T. Chem. Mater. 2007, 19, 3479-3483. doi:10.1021/cm0630340

47. Pu, S.; Li, H.; Liu, G.; Liu, W.; Cui, S.; Fan, C. Tetrahedron 2011, 67, 1438-1447. doi:10.1016/j.tet.2010.12.041

48. Liu, G.; Pu, S.; Wang, X. Tetrahedron 2010, 66, 8862-8871. doi:10.1016/j.tet.2010.09.066

49. Pu, S.; Liu, W.; Liu, G. Dyes Pigm. 2010, 87, 1-9. doi:10.1016/j.dyepig.2010.01.015

50. Pu, S.; Liu, W.; Miao, W. J. Phys. Org. Chem. 2009, 22, 954-963. doi:10.1002/poc. 1545

51. Liu, G.; Pu, S.; Wang, X.; Liu, W.; Fan, C. Dyes Pigm. 2011, 90, 89-99. doi:10.1016/j.dyepig.2010.12.007

52. Tian, H.; Wang, S. Chem. Commun. 2007, 781-792. doi:10.1039/B610004J

53. Fukaminato, T.; Sasaki, T.; Kawai, T.; Tamai, N.; Irie, M. J. Am. Chem. Soc. 2004, 126, 14843-14849. doi:10.1021/ja047169n

54. Zhang, J.; Tan, W.; Meng, X.; Tian, H. J. Mater. Chem. 2009, 19, 5726-5729. doi:10.1039/B908707A 
55. Fan, C.; Pu, S.; Liu, G.; Yang, T. J. Photochem. Photobiol., A: Chem. 2008, 197, 415-425. doi:10.1016/j.jphotochem.2008.02.004

56. Pu, S.; Fan, C.; Miao, W.; Liu, G. Tetrahedron 2008, 64, 9464-9470. doi:10.1016/j.tet.2008.07.073

57. Bonifazi, D.; Scholl, M.; Song, F.; Echegoyen, L.; Accorsi, G.; Armaroli, N.; Diederich, F. Angew. Chem., Int. Ed. 2003, 42, 4966-4970. doi:10.1002/anie.200352265

58. Browne, W. R.; de Jong, J. J. D.; Kudernac, T.; Walko, M.; Lucas, L. N.; Uchida, K.; van Esch, J. H.; Feringa, B. L. Chem.-Eur. J. 2005, 11, 6414-6429. doi:10.1002/chem.200500162

59. Browne, W. R.; de Jong, J. J. D.; Kudernac, T.; Walko, M.; Lucas, L. N.; Uchida, K.; van Esch, J. H.; Feringa, B. L. Chem.-Eur. J. 2005, 11, 6430-6441. doi:10.1002/chem.200500163

60. Moriyama, Y.; Matsuda, K.; Tanifuji, N.; Irie, S.; Irie, M. Org. Lett. 2005, 7, 3315-3318. doi:10.1021/ol051149o

61. Zheng, C.; Pu, S.; Xu, J.; Luo, M.; Huang, D.; Shen, L. Tetrahedron 2007, 63, 5437-5449. doi:10.1016/j.tet.2007.04.049

62. Pu, S.; Yang, T.; Xu, J.; Shen, L.; Li, G.; Xiao, Q.; Chen, B. Tetrahedron 2005, 61, 6623-6629. doi:10.1016/j.tet.2005.04.044

63. Tsai, F.-C.; Chang, C.-C.; Liu, C.-L.; Chen, W.-C.; Jenekhe, S. A. Macromolecules 2005, 38, 1958-1966. doi:10.1021/ma048112o

64. Zhan, X.; Liu, Y.; Wu, X.; Wang, S.; Zhu, D. Macromolecules 2002, 35, 2529-2537. doi:10.1021/ma011593g

65. Perrier, A.; Maurel, F.; Aubard, J. J. Photochem. Photobiol., A: Chem. 2007, 189, 167-176. doi:10.1016/j.jphotochem.2007.01.030

66. Kim, E.; Kim, M.; Kim, K. Tetrahedron 2006, 62, 6814-6821. doi:10.1016/j.tet.2006.04.089

\section{License and Terms}

This is an Open Access article under the terms of the Creative Commons Attribution License (http://creativecommons.org/licenses/by/2.0), which permits unrestricted use, distribution, and reproduction in any medium, provided the original work is properly cited.

The license is subject to the Beilstein Journal of Organic Chemistry terms and conditions:

(http://www.beilstein-journals.org/bjoc)

The definitive version of this article is the electronic one which can be found at: $\underline{\text { doi:10.3762/bjoc. } 8.114}$ 